\title{
OS SENTIMENTOS DA FAMÍLIA FRENTE A FACTICIDADE DA DOENÇA MENTAL ${ }^{1}$ THE FAMILY FEELINGS FACING THE FACT OF A MENTAL ILNESS LOS SENTIMIENTOS DE LA FAMILIA FRENTE AL HECHO DE LA ENFERMEDAD MENTAL
}

Adriane M. Netto de Oliveira*

RESUMO: Trata-se de uma reflexão sobre os sentimentos vivenciados pela família ao deparar-se com o diagnóstico médico da doença mental num de seus membros, evidenciando os momentos de fragilidade emocional deste grupo social. Ressalta-se também, a relevância da intervenção da equipe de saúde, através de um cuidado humanizado, como forma de ajudar a família a enfrentar e superar esta situação. A experiência da doença mental, vivenciada pela família é abordada, a partir do referencial teórico-filosófico de Martin Heidegger, priorizando um dos seus existenciais: a afetividade.

DESCRITORES: Saúde da família; Equipe de cuidados da saúde; F ilosofia em Enfermagem; Saúde mental.

\section{INTRODUZINDO O TEMA}

No decorrer da minha trajetória profissional, a necessidade de considerar a família como um grupo que precisa ser atendido, a fim de se sentir mais instrumentalizada para cuidar de seu familiar doente, tem sido uma constante interrogação para mim. Ao longo desta caminhada, tenho percebido que, freqüentemente, a família está distante do seu familiar doente, no sentido de não ser cuidada, nem tampouco participar e se envolver com o cuidado do seu familiar, possivelmente, por não ser reconhecida sua condição de "ser humano" na relação com os profissionais de saúde. Também, pude perceber que, muitas vezes, os profissionais de saúde não conseguem ter a sensibilidade e habilidade necessárias, na relação interpessoal com a família do ser portador de doença mental, para atender à sua necessidade de apoio e suporte emocional diante da facticidade da doença.

Quase sempre, o convívio com o ser portador de doença mental produz uma grande sobrecarga familiar, que acaba comprometendo a saúde, a vida social, a relação com os outros, o lazer, a disponibilidade financeira, a rotina doméstica, o desempenho profissional ou escolar, trazendo inúmeros outros comprometimentos para a família. Por outro lado, a interação da família com os serviços de saúde mental também é fonte de estresse, pois, geralmente, o contato com os profissionais de saúde resulta numa experiência frustrante, confusa e humilhante, em função desses profissionais desconhecerem não só o significado de vivenciar esta experiência para a família, como também seus sentimentos, dúvidas, incertezas, necessidades e desejos.

P rovavelmente, a partir da compreensão do significado de vivenciar a doença mental para a família, o cuidado a estes seres possa se dar de maneira mais compreensiva e humanizada, possibilitando que sejam mais bem atendidas.

\section{TRAJ ETÓRIA FENOMENOLÓGICA}

Este trabalho é uma pesquisa qualitativa, de inspiração fenomenológica. Nesse estudo, o que importou não foi a doença mental em si, mas os seres que a vivenciam e que, ao vivenciá-la, não perdem a dimensão ontológica de ser, por isso, são merecedores de respeito, de dignidade e de valor na sua existência. Ao interrogar

Recebido em 10/05/01 aceito em 20/08/01

\footnotetext{
Este texto foi extraído da dissertação de mestrado: “Compreendendo o significado de vivenciar a doença mental na família - um estudo fenomenológico e hermenêutico". Constitui-se num recorte da dissertação, que mostra um pouco da fragilidade das relações familiares frente ao impacto da manifestação da doença mental em de seus membros. A dissertação foi defendida em fevereiro de 2000.

* Professora Assistente I, da Disciplina de Enfermagem Em Saúde Mental do Departamento de Enfermagem, da Fundação Universidade Federal do Rio Grande- FURG - Mestrado Expandido Em Assistência de Enfermagem, da Universidade Federal de Santa Catarina - UFSC. Endereço: Dr. Bruno de Mendonça Lima, 36 - J ardim do Sol.- Rio Grande - RS Telefone: (53) 2352358. E-mail: cunhanet@ vetorialnet.com.br. Fax: (53) 2328941.
} 
as famílias, o objetivo foi ouvindo-as, compreender como descrevem e vêem o seu real vivido, o que possibilitou uma análise dos significados revelados em seus discursos, permitindo conhecer e compreender a existência da família como ser-no-mundo ${ }^{2}$ e ser-com. ${ }^{3}$

A tendência atual da enfermagem é a de retomar e reconsiderar o ser em seu todo e não mais isoladamente, em partes. 0 ser portador de doença mental não é apenas alguém que tem uma doença, mas é, acima de tudo, um produto existencial da sua condição de vida, levando em consideração que estes seres expressam, em sua doença, toda uma estrutura cultural, social, emocional e econômica advinda do seu meio ambiente, onde se encontra a sua família que, também, faz parte deste ambiente, não podendo, portanto, encontrar-se dissociada deste cuidado.

A opção por uma pesquisa de inspiração fenomenológica, surgiu em função do conhecimento que pretendi buscar, porque não estava claro para mim, como se dava o cuidado prestado à família do ser portador de doença mental no afazer cotidiano do cuidado em saúde mental. Viver num cotidiano atarefado, muitas vezes, limita a possibilidade de enxergar e perceber a essência do cuidado em saúde: o ser, por isso, essa pesquisa buscou des-velar esse ser família que vivencia a doença mental.

Os seres deste estudo foram as famílias que experenciam a facticidade da doença mental na sua coexistência cotidiana, cuidando de um familiar portador desta doença, que vivenciou, no mínimo, um surto psicótico, que freqüentava ou havia freqüentado o Centro de Atenção à Saúde Mental do município e que se dispuseram a participar desta pesquisa. 0 Centro de Atenção à Saúde Mental da Secretaria Municipal da Saúde iniciou suas atividades em 1994, com dois profissionais da área da psicologia e, atualmente, conta com diversos profissionais de diferentes áreas, que compõem o trabalho realizado na área da saúde mental, entre eles: psiquiatra, psicólogos, assistente social, enfermeira e outros. A clientela atendida compõe-se de crianças, adolescentes, adultos e idosos, que vêm do município e das ilhas adjacentes, em busca de atendimento, de maneira espontânea ou encaminhados por algum profissional. Neste local, estagiavam acadêmicos de Enfermagem e de Psicologia, tendo-se constituído no primeiro acesso às famílias.

As famílias deste estudo apresentaram uma característica em comum, queriam cuidar do seu familiar doente em casa e, se possível, instrumentalizar-se para cuidá-lo ainda melhor, a fim de evitar a internação no hospital psiquiátrico, que é um fator que desorganiza bastante a vida familiar, além de não se sentirem preparadas emocionalmente, para enfrentar esta internação. Entretanto, sabe-se que, nem sempre, a família que convive com um familiar portador de doença mental consegue cuidá-lo, ou seja, muitas vezes, a internação hospitalar constitui-se num dos meios para que estes seres possam recuperar suas forças, de maneira a suportar a sobrecarga de continuar cuidando do seu familiar.

A participação das famílias foi voluntária, sendo solicitada, por escrito, a autorização de cada familiar que participa dessa co-existência, tanto para participar da pesquisa, como para gravar as entrevistas que foram realizadas.

\section{OPÇÃO POR HEIDEGGER}

No decorrer da minha trajetória profissional, a preocupação com os seres que sofrem tem me inquietado, o que me faz acreditar que os profissionais de saúde têm compromissos com o cuidar do outro. Buscando fugir do modelo biomédico, cuja preocupação encontra-se, fundamentalmente, na parte doente do ser, deixando de lado, na maioria das vezes, o ser doente e o contexto no qual está inserido, é que busquei, em Martin Heidegger, um suporte teórico-filosófico que me permitiu, não só, afastar-me deste modelo de cuidar, mas, também, repensar idéias e conceitos em relação à maneira de cuidar do outro.

Ser-No-Mundo: são as múltiplas maneiras que o ser humano vive e pode viver; são os vários modos como ele se relaciona e atua com entes que encontra e a ele se apresenta (Heidegger, 1981, p.16)

3 Ser - Com: significa como me relaciono, atuo, sinto, penso, vivo com o ser (Heidegger, 1981, p.18). 
Heidegger questiona, procurando caminhos de aproximar o evidente, o simples, o fundamental que ficou esquecido, escondido e enterrado pelo raciocínio pragmático e tecnológico: o ser-aí. ${ }^{4}$ Neste esquecimento, encontra-se, também, a existenciália do ser-aí, que são maneiras características de se relacionar e de viver, sem as quais a vida não teria sentido, por isso, um dos temas que surgiu, ao longo da análise dos discursos foi a afetividade, em que desvelo alguns dos sentimentos vivenciados pela família frente à manifestação da doença mental no seu familiar.

Os discursos foram analisados à luz do referencial existencialista de Martin Heidegger, para tanto, busquei uma fundamentação na obra do próprio filósofo e no pensamento de outros autores que já utilizaram e interpretaram este referencial. Também, foram utilizados autores da área de saúde mental, que pudessem dar uma maior sustentação teórica aos dados e favorecer sua compreensão.

Dentre os vários temas e subtemas que surgiram ao longo da análise dos discursos, selecionei o subtema: afetividade, a fim de evidenciar os sentimentos vivenciados pela família do ser portador de doença mental, diante da facticidade da doença.

\section{DESVELANDO OS SENTIMENTOS DA FAMÍLIA}

A convivência cotidiana caracteriza-se por um constante estar com os outros. O ser-aí não apenas "é" e "está" no mundo, mas também se relaciona com os outros seres humanos: "Neste estar frente a frente, abrese para o mundo, toca e se deixa tocar por outros, sendo pois,atingido por esta situação. Fato este que, na analítica existencial heideggeriana, refere-se ao encontrar-se ou a afetividade" (Crossetti, 1997, p.75).

Para Heidegger, nos encontramos sempre numa situação afetiva, ou seja, estamos no mundo sempre em um determinado estado de ânimo. As experiências, pelas quais os seres humanos passam, não acontecem sem nenhum significado; muito pelo contrário, elas podem ser agradáveis, prazerosas, temíveis ou indiferentes; determinam o nosso modo de ser e como nos sentimos no mundo, tristes, alegres, tranqüilos ou com medo. A pre-sença como disposição refere-se aos afetos e sentimentos, ao estado de humor: "O humor revela como alguém está e se torna" (Heidegger, 1997, v.1, p.188).

Quando a família do ser portador de doença mental propõe-se a atribuir um significado à experiência que vivencia, geralmente, emergem vários sentimentos que envolvem o seu modo de ser-no-mundo, entre eles, um profundo sofrimento e angústia ao deparar-se com a manifestação da crise aguda da doença:

"Ah, fiquei triste, porque eu achei que o meu irmão vivia sempre bem comigo, está certo, ele era chatinho de vez em quando, mas era um irmão que fazia coisa boa para mim, me ajudava no colégio, era brabo, mas era para o meu bem que ele fazia as coisas, então eu fiquei triste. Pô, o meu irmão mudou, de repente ele virou completamente." (F1- Irmã).

"Ah, foi muito duro. A primeira internação é uma situação muito difícil. Bah, vou te dizer uma coisa, a princípio te choca profundamente, quase como uma perda daquele ente querido, como me foi dito por uma médica: a senhora está de luto." (F2- Mãe).

"Eu tenho um arrepio do hospital, só penso assim: que Deus ajude que nunca mais dê crise, porque se der e eu tiver que levar ele para lá de novo, não sei como é que vai acontecer ... porque eu acho que se me explicar o que posso fazer, eu poderia fazer em casa". (F 1- Mãe).

Em determinados momentos, a família apresenta uma certa ambigüidade de sentimentos, que se manifesta em resposta as atitudes agressivas do seu familiar doente, sentindo impotência e mágoa, pois não entende o porquê de ser agredida. Existe o reconhecimento de que o familiar doente é uma pessoa boa, quando fora da crise:

Ser - Aí: no olhar heideggeriano, não é apenas ser; é ser-aí num dado momento, é ser e ter um espaço e um tempo. 0 espaço na fenomenologia é possibilidade e o tempo é engajamento. Espaço é poder-ser, tudo é possível até a impossibilidade (Souza, 1998). 
“O mano, já não é tanto... é meu amigo, me trata bem quando não está doente, porque quando está doente é uma coisa ... é uma fera comigo, mas quando está bem, não, é meu amigo. (...) Eu sei que não é dele aquilo, eu entendo. A té, de vez em quando, fico meio chateada ... mas eu entendo. A mãe fala comigo, conversa, diz que não é dele, aí eu entendo, sei que quando ele está bom, não é assim". (F 1- Irmã).

Quando a família assume o cuidado do seu familiar, provavelmente, traz consigo a disposição para oferecer alguns elementos essenciais da vida, tais como, carinho e atenção, que são indispensáveis no modo eficiente de cuidar e, na maioria das vezes, não são encontrados na relação do ser portador de doença mental com o profissional de saúde que, geralmente, não tem essa disposição. Disposição para Heidegger, refere-se ao: "estado de humor. 0 humor revela como alguém está e se torna. (...) 0 humor não vem de fora, nem de dentro, ele cresce a partir de si mesmo, como modo de ser-no-mundo" (1997, v.1, p. 190 -191).

A disposição da família em cuidar do seu familiar doente, como um dos modos de vivenciar a doença mental, constitui-se num modo eficiente de cuidado, porque ela se envolve e se preocupa com a dor e 0 sofrimento do outro, oferecendo-Ihe apoio e solidariedade. Quando a família cuida do seu familiar de modo eficiente, sua pre-sença ${ }^{5}$ torna-se imprescindível para a recuperação deste ser. 0 cuidado, nesta condição, significa oferecer a ajuda que seu familiar necessita, auxiliando-o no seu fortalecimento, num momento de fragilidade emocional como ocorre na manifestação da doença mental.

Nas primeiras vezes em que ocorrem as crises agudas, geralmente, a família, apesar do medo, sentese mais esperançosa, pois o desconhecimento do diagnóstico médico da doença e/ou do seu possível significado, permite, ainda, a crença na cura e a sua maior preocupação gira em torno desta possibilidade. A visualização do seu familiar como alguém que, aparentemente, voltou ao "normal", completamente recuperado após a primeira internação, parece servir como um suporte que sustenta a esperança de um porvir melhor. Os discursos abaixo, revelam o sentimento de esperança da família:

"Ele tem um problema sim, eu não acredito que ele não vai ter cura, para mim isso aí tem cura. Eu tenho uma pessoa que tem um problema mental, só que eu não acredito que seja só um problema mental, eu acho que isso aí tem cura, tanto que agora, a gente vê que ele está normal. Se bem que, ele já teve um ano sem ter nada, nada, super normal, trabalhando e tudo e voltou a ter crises de novo, só que, a meu ver, eu acho que isso aí tem cura". (F1- Mãe).

“... a gente achava que aquilo ia passar, ela saiu muito bem a primeira vez, só a primeira vez". (F2- Mãe).

Entretanto, este sentimento de esperança tende a desaparecer quando o diagnóstico médico lhes é comunicado. Mas, aos poucos, pode emergir novamente, o sentimento de esperança quanto à cura, como mais um recurso para fortalecer sua existência diante da facticidade da doença; essa esperança é reforçada quando o familiar portador de doença mental apresenta manifestações de um comportamento socialmente aceitável, diferente daquele manifestado na crise aguda. Emerge, então, a crença de que, talvez, seu familiar possa recuperar-se totalmente e voltar a ser, como era, anteriormente, à manifestação da doença.

A esperança de cura é ainda o sentimento que estimula a família a lutar contra a doença do seu familiar. A família, freqüentemente, sente-se impotente e despreparada em relação ao que fazer para melhor cuidar do seu familiar quando este entra em crise, reconhecendo que é possível manter uma boa convivência com ele, desde que siga corretamente o tratamento. Quando a esperança faz parte dos sentimentos da família, esta constitui-se num dos caminhos para continuar lutando pelo bem-estar do seu familiar portador de doença mental, acreditando que, se ele voltou para casa bem, não há porque considerá-lo como doente. A esperança faz com que a família espere um futuro melhor do que o atual para o seu familiar doente. Para Heidegger, o caráter de humor reside em ter esperança, "Aquele que tem esperança se carrega, a si mesmo para dentro da esperança, contrapondo-se ao que é esperado" (1997, v.2, p.143).

Esse ente que cada um de nós somos e que, entre outras, possui em seu ser a possibilidade de questionar, é designado com o termo pre-sença. A presença se compreende em seu ser, isto é, sendo: "É próprio deste ente que seu ser se lhe abra e manifeste com e por meio de seu próprio ser, isto é, sendo. A compreensão do ser é em si mesma uma determinação do ser da pre-sença" (Heidegger, 1997, v.1, p.38). 
A família carrega consigo a esperança, também como um suporte, ampliando sua visão em relação a doença, no sentido de acreditar que, após a superação da crise aguda, provavelmente seu familiar terá condições de ser-no-mundo, com múltiplas possibilidades de ser, não aprisionando-o ao diagnóstico médico, mas, pelo contrário, liberando-o para poder ser. ${ }^{6}$

Enquanto a família mantiver a esperança como suporte para enfrentar a doença, muitos caminhos poderão ser percorridos em busca da saúde mental de todos, na relação familiar. No decorrer das reinternações, a família vai percebendo que, talvez, a cura, tradicionalmente conhecida como "não ter mais a doença", não ocorra. Mas, a família passa a acreditar na possibilidade de cura como as várias possibilidades de manter uma boa qualidade de vida, desde que o seu familiar doente assuma o tratamento como parte integrante da vida atual. Por vezes, vem a falta de esperança na cura que, também, é um modo de ser autêntico da família que vivencia a facticidade da doença. Heidegger (1997, v.2, p.15), considera que a falta de esperança, "não retira a presença de suas possibilidades, sendo apenas um modo de ser para essas possibilidades". Os discursos abaixo, desvelam a insegurança da família frente a manifestação da doença e o medo diante da revelação do diagnóstico médico:

“... queria alguém para me socorrer, um médico para chegar e me esclarecer o que é isso aí, será que tem cura, será que não tem, eu ainda não cheguei nesse ponto aí". (F1- Mãe).

"Eu acho que, das primeiras crises que deu nele, quando ele voltou, me sentia mais segura do que agora. Eu não sabia o que ele tinha, então eu dizia assim: meu filho deu alta, está curado. Agora, eu não tenho sossego como das outras vezes, porque sei que ele deu alta, mas não está curado". (F 1- Mãe).

"Eu tenho medo de ficar com ele, quando ele está assim ... não digo para ele, mas tenho medo, porque eu sei que ele não está normal ... ele fica diferente comigo e só comigo que ele implica, tenho medo que ele se revolte comigo, me xingue, me dê, faça alguma coisa. Aí, não sei como é que eu vou fazer, como vou reagir, se ele começar a me xingar e eu estiver sozinha com ele dentro de casa. Quando ele está bom, eu não tenho medo de ficar com ele, mas doente, eu tenho medo". (F 1- Irmã).

0 modo de ser autêntico da família que se angustia frente ao desconhecimento da doença mental, despreparada para enfrentar o problema, faz com que perca a esperança da cura, num primeiro momento, considerando a doença como sinônimo de finitude da existência do seu familiar.

Numa visão heideggeriana, a cura são as infinitas possibilidades que proporcionam ao ser humano encontrar-se consigo mesmo e reconhecer aspectos para o seu poder-ser, existindo e respondendo à sua existência com autenticidade, mostrando-se como ser detentor de vontade e decisão próprios. Heidegger considera que a cura constitui a totalidade do todo estrutural da pre-sença, "E ntretanto, o momento primordial da cura, o 'preceder-a-si-mesma', significa que a pre-sença existe cada vez, em função de si mesma. 'Enquanto ela é' e até o seu fim, a pre-sença se relaciona com o seu poder ser" (1997, v.1, p.15).

Para Heidegger, todos os comportamentos e atitudes são dotados de cura e guiados por uma dedicação, "A cura é aquilo a que pertence a pre-sença humana enquanto vive" (1997, v.1, p.264). Ele insiste que é preciso pensar a preocupação, a ocupação e a dedicação como cura, o que significa que esta pode encontrar-se em todo comportamento e situação da vida humana. A cura, numa visão heideggeriana, pode ser proporcionada por um cuidado eficiente que favoreça ao ser humano ter um projeto de vida, assumindo o seu ser, tornando-se livre para reconhecer e escolher suas próprias possibilidades. Para o ser portador de doença mental, provavelmente, esta pode acontecer quando ele vivencia a sua doença de modo autêntico, reconhecendo que é necessário cuidar-se e responsabilizar-se por si, para ter uma boa qualidade de vida.

A preocupação com o bem-estar do familiar doente pode ser uma constante na existência destas famílias, buscando, em suas tomadas de decisão, confortá-lo. 0 cuidado parece constituir a essência da relação

No modo de ser que se constitui através do existencial do projeto, a pre-sença é sempre "mais" do que é de fato. No pensamento heideggeriano, "Projeto é a estrutura, é a forma de ser do homem que só existe projetando-se para suas possibilidades, o projeto é a ação do homem em busca do seu poder-ser. Os comportamentos humanos sempre são realizações de possibilidades ou adoção de modos possíveis de ser" (Crossetti, 1997, p. 71). 
com o outro, no convívio cotidiano dessas famílias. A preocupação com o ser doente, evidencia-se no contato direto com as famílias que vivenciam o processo de doença com profunda dor; referem, por vezes, sentir-se também doentes ou, até mesmo, adoecem por não saberem lidar com aquilo que reconhecem como problema, mostrando-se inseguras quanto ao que fazer diante de um ser que amam e que, aparentemente, não melhora frente ao cuidado prestado:

"F oi muito doloroso, doeu muito, muito, ainda está doendo, porque eu só me sinto bem quando ele está, como está agora ... que ele está bem, que ele se cuida, ele mesmo toma banho. Ele está bem, eu estou super bem, agora, quando ele está em crise, para mim parece que o mundo desabou em cima de mim. Sinto que eu fico doente, fico me segurando para poder segurar as pontas dele, mas sinto assim, que eu estou doente, então fico procurando muita ajuda". (F1- Mãe).

Ao deparar-se com o diagnóstico da doença mental, além dos vários sentimentos envolvidos, a família, algumas vezes, acredita não poder sonhar mais com um futuro próspero, uma vez que o enfrentamento da loucura parece dar a sensação de limitação total em relação ao poder-ser daquele que manifestou a doença. Ao mesmo tempo, a visão da doença mental como invalidez e incompetência, presente nos profissionais, na família e na sociedade, em geral, contribui para reforçar, cada vez mais, a desesperança e o descrédito no por vir do ser doente. Provavelmente, enquanto houverem pessoas pensando desta forma, mais difícil será buscar o potencial para a saúde do ser portador de doença mental e ajudar na reestruturação da família.

A própria família reconhece que a recorrência da manifestação do surto psicótico pode levar a perda daquele ser, até então, considerado como "normal". Atrelado a isto, vem a angústia de não reconhecerem melhoras no seu familiar, por vezes, acreditando que não há mais esta possibilidade em sua existência. Acreditar na potencialidade do ser portador de doença mental é pré-condição para que ele possa se mostrar e melhorar sua condição de saúde.

A tomada de consciência da existência da doença mental na família, na maioria das vezes, processase ao longo dos anos desta convivência, permitindo à família ter uma nova percepção em relação à doença, levando-a a reconhecer que, provavelmente, as perspectivas de cura não existem mais. Entretanto, parece haver uma melhor aceitação desta situação, desde que o seu familiar doente possa ser-no-mundo. Essa coexistência autêntica da família com o seu familiar portador de doença mental pode representar a pre-sença deste ser como cura, numa visão heideggeriana, o que significa procurar e encontrar caminhos que possam ajudá-lo a viver bem no mundo, apesar da doença.

A doença provoca uma agressão na vida dos seres humanos afetados por ela, tornando o futuro incerto (Olivieri, 1985). A incerteza provocada pela doença mental é, na maioria das vezes, desgastante para a família que cuida do familiar doente, porque não sabe se pode ter uma perspectiva melhor de futuro, já que a melhora do seu familiar depende, em grande parte, do seu desejo em engajar-se no cuidado. Esse cuidado inclui uma variedade de cuidados, entre eles, a terapia medicamentosa, o acompanhamento por uma equipe multiprofissional, a disponibilidade da família e da comunidade, para que juntos, possam ajudar o ser portador de doença mental de maneira significativa. Faz-se necessário, também, que a família seja cuidada para adquirir coragem e forças de modo a continuar cuidando do seu familiar portador de doença mental, bem como, para que possa superar, de maneira menos sofrida a facticidade da doença em sua existência, a partir de uma relação mais envolvente e humanizada com os cuidadores.

\section{ALGUMAS REFLEXÕES}

A vivência da facticidade da doença mental, na família, pode ser permeada por vários sentimentos, entre eles, a tristeza, a angústia, o medo, a esperança e a desesperança, bem como, um intenso sofrimento que a acompanha, toda vez que seu familiar doente entra na crise aguda da doença. No período inicial da doença, a esperança e a crença de que seu familiar vai ficar curado parece ser algo que se faz presente; entretanto, quando começa a surgir a necessidade de várias reinternações no hospital psiquiátrico, vem, então, 
a desesperança em relação às possibilidades de poder-ser do familiar doente. Nesse momento de desesperança, é que a equipe de saúde pode tornar-se uma fonte de apoio e sustentação para a família, oferecendo-Ihe a coragem e a ajuda que se fizer necessária, para que ela não desanime diante da exaustiva tarefa de cuidar do seu familiar portador de doença mental, bem como, na busca de caminhos para que ela possa se fortalecer e, também, valorizar o seu poder-ser e o do seu familiar doente.

Desde a sua manifestação e em todas as fases da doença, a família necessita de ajuda, mas o impacto inicial, provavelmente, é o que causa maior desestruturação, tornando-se imprescindível a solidariedade com o seu sofrimento e a sua dor, permitindo aflorar, no cuidado, a sensibilidade humana do profissional de saúde, para que possa compreender a dimensão existencial desse momento, para a família e, assim, poder cuidá-la de modo eficiente. $\mathrm{Na}$ medida em que houver um comprometimento maior dos profissionais de saúde na relação com essas famílias, provavelmente, seja possível resgatar a esperança, como uma meta contínua daqueles que cuidam e são cuidados. No pensamento heideggeriano, a falta de perspectiva num futuro melhor, petrifica a existência; por isso, a manutenção do sentimento de esperança é o instrumento que a família dispõe de um amanhã melhor e com menor sofrimento.

A família, na maioria das vezes e, principalmente, no período inicial de manifestação da doença, vivencia tal situação de maneira inautêntica, porque não admite esta facticidade em sua vida. Posteriormente, com a conscientização da doença, parece começar a vivenciá-la com autenticidade, passa a aceitá-la e a buscar caminhos que possam favorecer a saúde mental de todos os envolvidos neste processo de enfrentamento da doença. A aceitação da doença constitui-se num elemento essencial para compreender melhor o seu familiar portador de doença mental, bem como, faz-se necessária a intervenção dos profissionais de saúde, para que a família não fique apoiada no desvalor da doença e sim, tenha forças para buscar o potencial para a saúde do seu familiar.

Ao desvelar os sentimentos da família, diante da manifestação da doença mental, parece ficar evidente a necessidade de um maior comprometimento dos profissionais de saúde em cuidar da família e considerá-la como uma unidade de cuidado, para que ela possa continuar cuidando de si e do seu familiar doente, de maneira menos sofrida e mais saudável. Entretanto, este cuidado precisa ser humanizado, no sentido de envolver proximidade, diálogo, relações interpessoais significativas para o ser portador de doença mental e sua família e um escutar de modo compreensivo o sofrimento das pessoas envolvidas com a situação de doença.

ABSTRACT: It deals with a reflection about the feelings lived by a family realizing with a medical diagnostic of a mental illness in one of its members, showing the fragile emotional moments in this social group. It also highlights the intervention of a health team, through human care, as a way to help the family to face up and get over this situation. The mental illness experience, lived by the family is mentioned since the analysis done using Martin Heidegger, theoric-phylosophic reference, prioring one of his existents, the affectiviness.

KEY WORDS: Family health; P atient care team; P hilosophy nursing; Mental health.

RESUMEN: Se trata de uma reflexión sobre los sentimientos vividos por la familia al darse cuenta con el diagnóstico médico de la enfermedad mental en uno de sus miembros, evidenciando los momentos de fragilidad emocional de este grupo social. Se resalta también, la relevancia de la intervención del equipo de salud, a traves de un cuidado humanizado, como forma de ayudar la familia a enfrentar y superar esta situación. La experiencia de la enfermedad mental, vivida por la familia es abordada, a partir del análisis realizado, usando la referencia teórica-filosófica de Martin Heidegger, priorizando uno de sus existenciales: la afectividad.

PALABRAS CLAVES: Salud de la familia, G rupo de atencion al paciente, Filosofia en enfermeria; Salud mental. 


\section{REFERÊNCIAS}

1 CROSSETTI, M. da G. Processo de cuidar: uma aproximação à questão existencial na enfermagem. Florianópolis, 1997. Tese (Doutorado em Filosofia) - Universidade Federal de Santa Catarina.

2 HEIDEGGER, M. Ser e tempo. 6.ed. Petrópolis: Vozes, 1997. v. 1.

3 HEIDEGGER, M. Ser e tempo. 5.ed. Petrópolis: Vozes, 1997. v. 2.

4 HEIDEGGER, M. Todos nós ... ninguém- um enfoque fenomenológico do social. São Paulo: Moraes, 1981.

5 OLIVEIRA, A. M. N. de. Compreendendo o significado de vivenciar a doença mental na família - um estudo fenomenológico e hermenêutico. Florianópolis, 2000. Dissertação (Mestrado Em Assistência de Enfermagem) Universidade Federal de Santa Catarina.

6 OLIVIERI, D. P. O ser doente - dimensão humana na formação do profissional de saúde. São Paulo: Editora Moraes, 1985.

7 SOUZA, Í. Fenomenologia: uma abordagem metodológica heideggeriana. Florianópolis: Pós-Graduação em Enfermagem, 1998, UFSC, Notas de Curso Sobre Fenomenologia. 